\title{
Approach to Dynamic Fracture Toughness of GFRP from Aspect of Viscoelastic and Debonding Behaviors"
}

\author{
Savetlana SHIRLEY ${ }^{* *}$ and Hiroomi HOMMA ${ }^{* * *}$ \\ "* Mechanical Engineering Department, Toyohashi University of Technology, 1-1 Hibarigaoka, \\ Tempaku-cho, Toyohashi 441-8580 Japan, E-Mail: shirley@homma-tut.jp \\ "*tICCEED, Toyohashi University of Technology, 1-1 Hibarigaoka, \\ Tempaku-cho, Toyohashi 441-8580 Japan, E-mail: homma@icceed.tut.ac.jp
}

\begin{abstract}
Over the wide range of the loading rates, fracture toughness test have been carried out for the GFRP material. Fracture toughness based on the stress singularity is significantly affected by the loading rate, while one based on the strain singularity is less affected by the loading rate. Fracture toughness based on the strain can explain the fracture behaviors of viscoelastic materials, but to explain the loading rate effect completely, the debonding process between the glass fiber and the polymer matrix must be taken into account.
\end{abstract}

Key words: Dynamic Fracture Toughness, Viscoelastic, Glass Fiber Reinforced Polymer, Stress Intensity Factor, Strain Intensity Factor, Debonding, Damage

\section{Introduction}

Nowadays, fiber reinforced plastics (FRP) is widely used for structural and mechanical components and some of them are used under dynamic loading at various strain rates.

Some papers deal with the strain rate effect on the mechanical behaviour of $\mathrm{FRP}^{(1)-(2)}$. The dynamic uniaxial compression test of the unidirectional E-glass/vinyl ester composite indicated that the effect of the strain rate appeared on strength through the increase in modulus of the matrix material and the decrease of surface energy as the increase of loading rate ${ }^{(1)}$. The impulsive compression test of glass fiber-epoxy composite indicated that fiber buckling resulted in increase of energy absorption ${ }^{(2)}$. In this case, the short duration of the stress pulse did not allow the matrix to soften, but enhanced the stress beyond matrix/fiber interfacial strength. It caused the extensive bonding and lamination strength at a high strain rate.

The present work deals with the viscoelastic effect on the dynamic fracture toughness of the random chopped strand mat glass fiber reinforced polyester composite. Some papers investigated the static fracture characteristics of random short fiber-polymer composite ${ }^{(3)-(8)}$. Inelastic deformation in the process zone at the crack tip in FRP was associated with fiber debonding, pullout and breakage. Such inelastic deformation in FRP was localized onto a narrow region ahead of the crack tip unlike those in metallic materials ${ }^{(3)-(4)}$. Using the tension-softening concept and assuming a linear decay of stress within the process zone, Homer and $\mathrm{Li}^{(5)}$ indicated inelastic behaviour in the "process zone" ahead of the crack tip in a randomly distributed long fiber composite material. The process zone can appear in the extent that for the long fiber composite, the small-scale yielding conditions are not satisfied but for very short fiber of less than $0.5 \mathrm{~mm}$, the linear fracture mechanics requirements are satisfied.

In single-edge notched (SEN) specimens, the damage near the crack tip was observed at a very low level of applied load $\left(30 \%\right.$ of $\left.\mathrm{P}_{\max }\right)$. This damage consisted of debonding

${ }^{*}$ Received 7 Sep., 2006 (No. 06-0102) [DOI: 10.1299/jmmp.1.275] 
between fiber and matrix as well as matrix cracks parallel to the initial crack plane. The increase in toughness with fiber volume fraction resulted from the increasing of debonding sites with the fiber volume fraction and it is because the increase in the fiber volume fraction raises debonding energy. In addition, the debonding process in these materials is regarded as the most dominant energy absorbing mechanism ${ }^{(8)}$.

However, these works based on the LEFM do not take into account the viscoelastic effect in the discussion on the dynamic fracture toughness of FRP materials. In the dynamic fracture mechanics analysis of FRP, the viscoelastic effect cannot be neglected because of apparent viscoelastic property in FRP materials. The analytical results of natural frequencies and modal loss factor demonstrated that the dynamic response of FRP sandwich panels is affected by the viscoelastic properties of the material ${ }^{(9)}$.

There are limited numbers of papers concerning the viscoelastic role in the field of the dynamic fracture mechanics. Georgiadis ${ }^{(10)-(11)}$ investigated how the viscoelastic property of the material affects a time history of the dynamic stress intensity factor (SIF) after impact loading. The overshoot of dynamic stress intensity factor observed in a linear elastic material is suppressed in a viscoelastic material. Gunter ${ }^{(12)}$ analyzed the dynamic crack propagation under uniform tension and indicated that the energy release rate decreased as the damping property increased. It suggests that a large amount of energy is dissipated for viscous deformation and hence a less amount of energy is supplied for a new crack surfaces.

In the previous papers by the present authors ${ }^{(13)}$, Young's modulus of glass fiber reinforced plastic (GFRP) was measured for a wide range of strain rates. Dynamic fracture toughness of GFRP was also measured on the basis of linear fracture mechanics and it was twice as large as the static fracture toughness. The dynamic fracture toughness was 12 $\mathrm{MPa} \sqrt{ } \mathrm{m}$ in comparison with the static one of $7 \mathrm{MPa} \sqrt{\mathrm{m}}$.

In this paper, the fracture toughness is measured under an intermediate loading rate and the viscoelastic property of GFRP used for the experiment is identified for a wide range of strain rates. The obtained viscoelastic parameters are used for numerical analysis of the stress and strain fields ahead of the crack tip in order to examine the viscoelastic effect on the dynamic fracture toughness of GFRP. In addition, debonding process in a damage zone formed ahead of the crack tip is considered to understand the dynamic fracture toughness of GFRP.

\section{Measurement of Dynamic Fracture Toughness at an Intermediate Loading} Rate

\subsection{Experimental preparation}

Five millimeters thick of GFRP sheets were fabricated by hand lay up in the laboratory. The sheet was cured for four hours at $120^{\circ} \mathrm{C}$. Details of the fabrication and material properties are explained in the previous paper ${ }^{(13)}$. The mechanical property is listed again in Table 1.

Table 1 Mechanical Properties of GFRP

\begin{tabular}{|l|c|l|l|}
\hline Material Property & Polyester & Glass Fiber & GFRP Laminate \\
\hline Young's Modulus $(\mathrm{GPa})$ & 5.4 & 76.0 & 11.8 \\
\hline Density $\left(\mathrm{Kg} / \mathrm{m}^{3}\right)$ & 1165 & 2450 & 1440 \\
\hline
\end{tabular}

In this work, a fracture toughness test of GFRP is carried out at an intermediate loading rate. The three-point bend specimen depicted in Fig. 1 is used to measure the fracture toughness of GFRP. Because introduction of a fatigue initial crack is very difficult in the GFRP specimen, a narrow slit of $0.6 \mathrm{~mm}$ width is first cut and a fine slit of $0.1 \mathrm{~mm}$ width is further introduced from the wide slit edge. 
A fracture toughness test was carried out at the stress intensity rate $(\dot{K})$ of $1 \times 10^{3}$ $\mathrm{MPa} \sqrt{\mathrm{m}} / \mathrm{s}$ in accordance with the ASTM-E399 standard for the plain strain fracture toughness test for metallic materials. The stress intensity was measured using the strain gauge method $^{(14)}$. The $5 \%$ offset line method to define the crack initiation cannot be applied to the GFRP specimen, because the non-linearity in the load-deflection curve resulted from damage zone consisting of micro-cracking of the matrix, debonding of fibers and the matrix and fiber breaking. The crack initiation is defined as cracking more than $90 \%$ of through the thickness at the slit root of the specimen ${ }^{(15)}$.

The strain gauge position on the specimen is $7 \mathrm{~mm}$ distant from the crack tip as shown in Fig. 1.

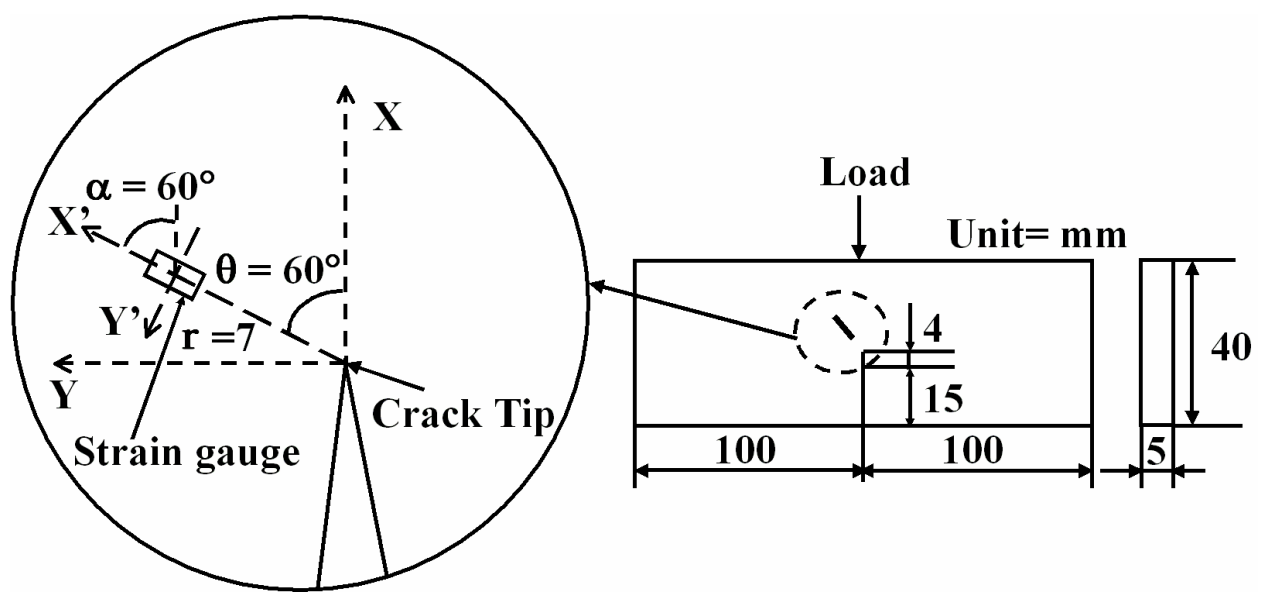

Fig. 1 Specimen Geometry and Loading Condition

Dally and Sanford ${ }^{(14)}$ proposed a method to precisely measure a stress intensity factor from the strain component in the $\mathrm{x}$ ' direction for $\mathrm{r}<\mathrm{a}$. The crack tip strain field in an isotropic elastic material can be expressed by an infinite power series, where the first term is a $1 / \sqrt{ } \mathrm{r}$ singularity, the second term is constant, the third term contains $V_{\mathrm{r}}$ and so on. If the special values are taken for $\theta$ and $\alpha$, the second and the third term vanish and the first term is given as:

$$
2 \mu \varepsilon_{x^{\prime} x^{\prime}}=\left(\frac{K_{I}}{2 \pi}\right) r^{-1 / 2}\left[k \cos \left(\frac{\theta}{2}\right)-\frac{1}{2} \sin \theta \sin \left(\frac{3 \theta}{2}\right) \cos 2 \alpha+\frac{1}{2} \sin \theta \cos \left(\frac{3 \theta}{2}\right) \sin 2 \alpha\right]
$$

where $\mu$ is shear modulus

The special values of $\theta$ and $\alpha$ are determined by the equations: $\cos 2 \alpha=-k=-(1-v) /(1+v)$ and $\tan (\theta / 2)=-\cot 2 \alpha$, where $v$ is Poisson's ratio. The stress intensity can be precisely calculated by Eq. (1) and the measured strain $\varepsilon_{\mathrm{x}}{ }^{\prime} \mathrm{x}$, at moderate distance from the crack tip. Since the Poisson's ratio of GFRP, $v$, is 0.33 , the value of $\theta$ and $\alpha$ are calculated as $60^{\circ}$. By substituting $60^{\circ}$ for $\theta$ and $\alpha$, Eq. (1) is rewritten as:

$$
K_{I}=E \varepsilon_{x^{\prime} x^{\prime}} \sqrt{\frac{8}{3} \pi r}
$$

where $\mathrm{K}_{\mathrm{I}}$ is the stress intensity factor, $\mathrm{E}$ is the Young's modulus, $\varepsilon_{\mathrm{x}}$ 'x' is the strain at the strain gauge position and $r$ is the distance from the crack tip to the strain gage.

\subsection{Experimental results}

In the experiment of the fracture toughness at intermediate loading rate, sixteen 
specimens were loaded up to several load levels so that the increasing rate of stress intensity can be $1 \times 10^{3} \mathrm{MP} \sqrt{\mathrm{m}} / \mathrm{s}$, and then unloaded. During the experiments, output of the strain gage mounted at the position $7 \mathrm{~mm}$ distant from the crack tip was recorded to calculate the stress intensity factor.

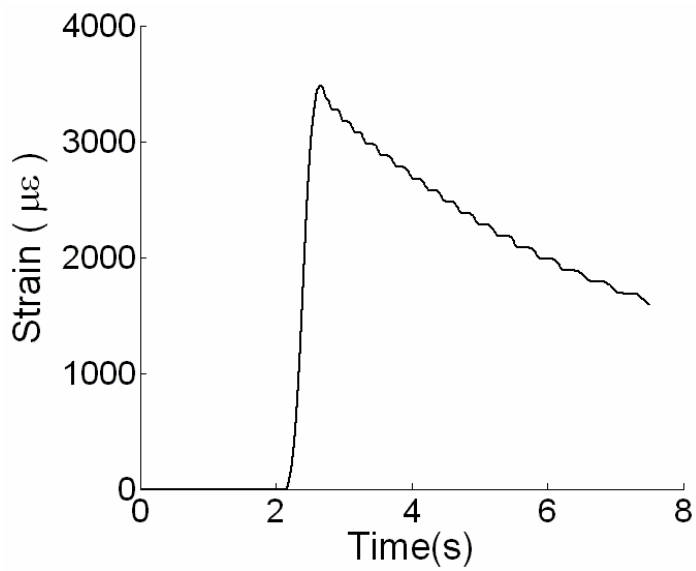

Fig. 2 Typical Curve of the Strain History of GFRP Obtained from the Strain Gauge Output

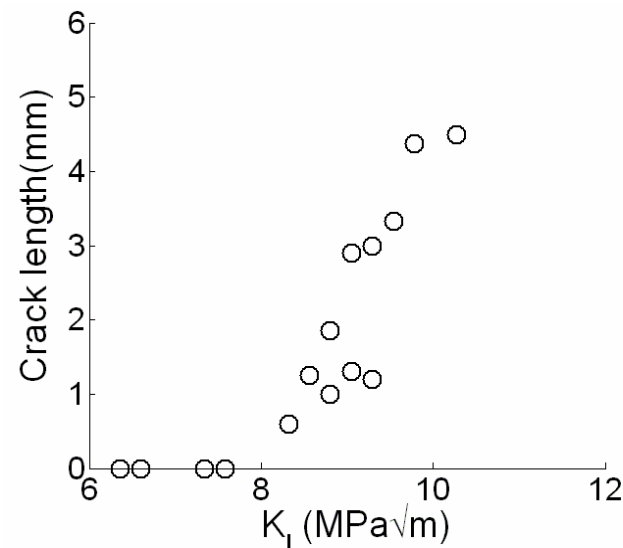

Fig. 3 Crack Growth Amount as a Function of Applied Stress Intensity

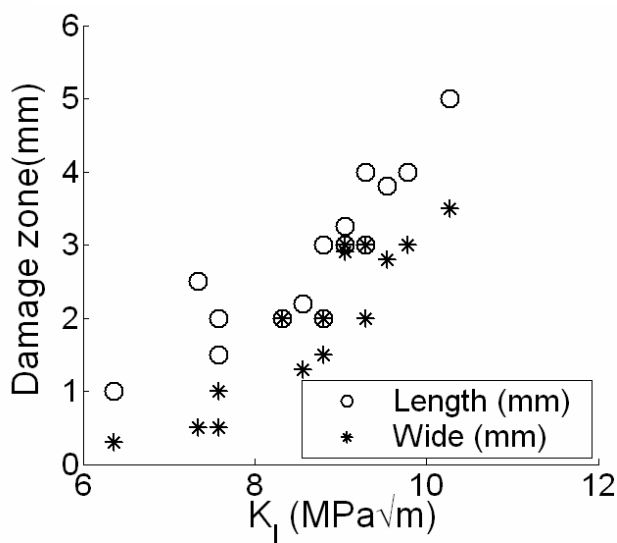

Fig. 4 Damage Zone as a Function of Applied Stress Intensity

The typical curve of the strain history of GFRP under intermediate loading rate is shown in Fig. 2. Unloaded specimens were cut to examine the crack initiation. In Fig. 3, the crack growth amount is plotted as a function of the applied stress intensity. Fracture toughness value for the crack initiation under the intermediate loading rate is defined as 8.3 $\mathrm{MPa} \sqrt{\mathrm{m}}$.

A similar damage zone to the previous experimental results ${ }^{(13)}$ is observed ahead of the crack tip. The sizes of the damage zone, width and length are plotted as a function of the applied stress intensity in Fig. 4. Under intermediate loading rate, the damage zone was formed at the stress intensity level of around $6.3 \mathrm{MPa} \sqrt{\mathrm{m}}$. The damage zone increases in both length and width with the applied stress intensity. Then, the width was saturated at around $3.5 \mathrm{~mm}$ and only the length increases. At the stress intensity level of the crack initiation, the damage zone size was around $2 \mathrm{~mm}$ in wide and length.

The scanning electron microscopic (SEM) observation was done for the examination of the damage at the crack initiation. One observation result is shown in Fig. 5. Fiber pulling out and fiber breaking are observed in the figure. The fibers located at rather off-center with respect to the crack plane are pulled out from the matrix, but those located at the center with respect to the crack plane are broken. 


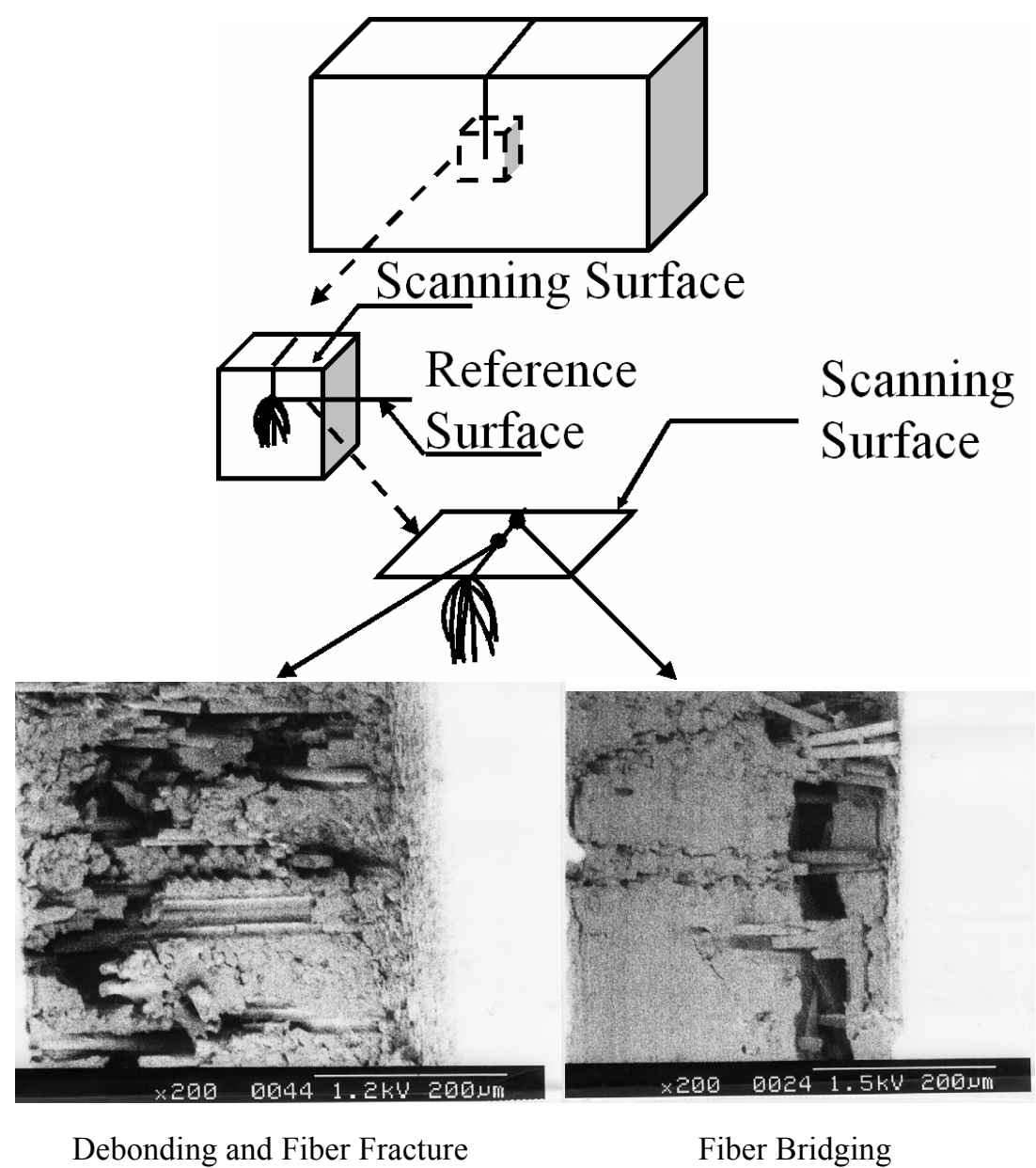

Fig. 5 Damage in Random Chopped Strand Mat Glass Fiber Reinforced Polyester under Intermediate Loading

3. Numerical Analysis

\subsection{Viscoelastic parameter}

Viscoelastic stress and strain analysis is carried out by the commercial finite element codes ANSYS, in which three parameters, long time shear modulus $\mathrm{G} \sim$, short time shear modulus $\mathrm{G}_{\mathrm{o}}$ and relaxation time $\tau$ are used to represent the viscoelastic properties.

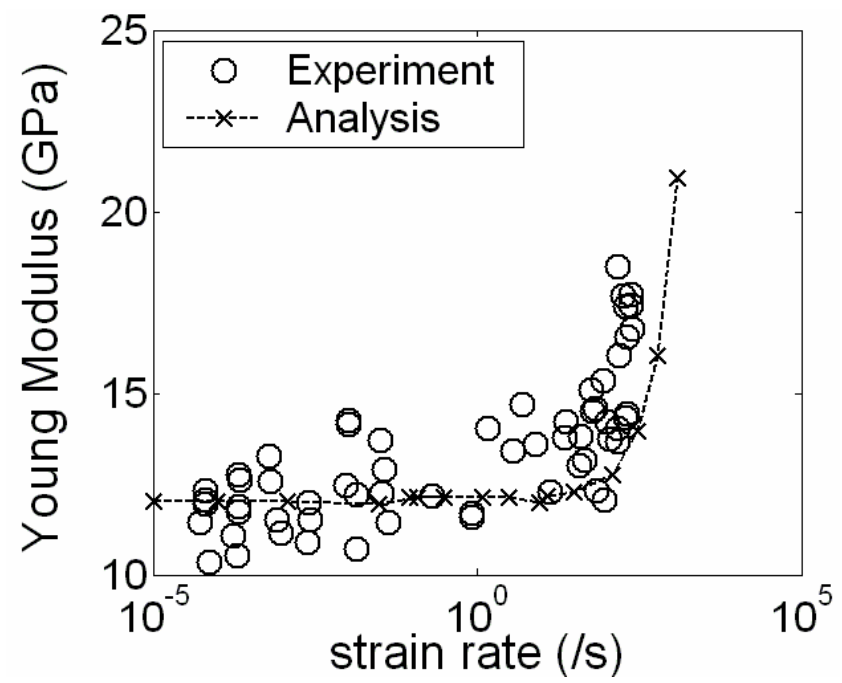

Fig. 6 Fitting Curve of the Young's Modulus as a Function of the Strain Rates 
Young's modulus tests in the previous work $^{(13)}$ are simulated by numerical analysis using the same specimen geometry and loading configuration as the three parameters are changed systematically in order to obtain the best agreement between the simulation and the experimental results. Young's modulus is defined as the slope of the linear part of the stress-strain curve. Finally, Young's modulus is plotted as a function of the strain rate and an appropriate set of $\mathrm{G} \sim, \mathrm{G}_{0}, \tau$ provides the best fit between the numerical and the experimental result as depicted in Fig. 6. Then $\mathrm{G} \sim, \mathrm{G}_{0}, \tau$ value are identified. These values are listed in Table 2.

Table 2 Identified Viscoelastic Parameters

\begin{tabular}{|c|c|}
\hline \multicolumn{2}{|c|}{$v=0.33$} \\
Density $=1440 \mathrm{Kg} / \mathrm{m}^{3}$ \\
\hline Viscoelastic & Elastic \\
\hline $\mathrm{G}_{0}=28.8 \mathrm{GPa}$ & $\mathrm{E}=11.8 \mathrm{GPa}$ \\
$\mathrm{G} \sim=13.5 \mathrm{GPa}$ & \\
$\mathrm{K}_{0}=70.4 \mathrm{GPa}$ & \\
$\tau=7.4 \times 10^{-2} \mathrm{~s}$ & \\
\hline
\end{tabular}

In Fig. 6, the close examination about the fitness between the calculated and the experimental result reveals that at low and medium strain rates the calculated Young's modulus is fitted with the experimental one. At high strain rates the calculation result is slightly shifted to the higher strain rates. Nevertheless, it can be seen that the good fitness is obtained over the wide range of strain rates.

\subsection{Stress and strain intensity factors}

\section{(1) Singularity}

Linear elastic fracture mechanics (LEFM) states that the singularity is present ahead of the crack tip. To validate the finite element mesh model used in this analysis, the calculation result under static loading is used to check whether the singularity is present ahead of the crack tip. In addition, for the static case, the stress intensity factor calculated by Eq. (2) using the strain at the strain gauge position is compared with the one calculated from the stress field ahead of the crack tip.

\section{(2) Mesh Model}

Viscoelastic material under static loading is considered as a linear elastic material. Static analysis is carried out using ANSYS 6.0. The minimum mesh size at the crack tip was $2 \mu \mathrm{m}$. A mesh model for a half of the three-point bend specimen shown in Fig. 1 is generated for the static and the intermediate loading rates as shown in Fig. 7.

In dynamic cases including the intermediate loading rate, the GFRP material is expected to behave in a viscoelastic manner. Then, the material properties of GFRP to be input for the analysis are density, Poisson's ratio and the three-viscoelastic parameters i.e. the long and the short time shear modulus and the relaxation time. Dynamic analysis is carried out using ANSYS 6.0 / LS-DYNA. A mesh model for the dynamic case is similar to the model for the static loading in Fig. 7, but the model length is shorten from $100 \mathrm{~mm}$ to 50 $\mathrm{mm}$ and the minimum mesh size at the crack tip is $0.4 \mu \mathrm{m}$. 


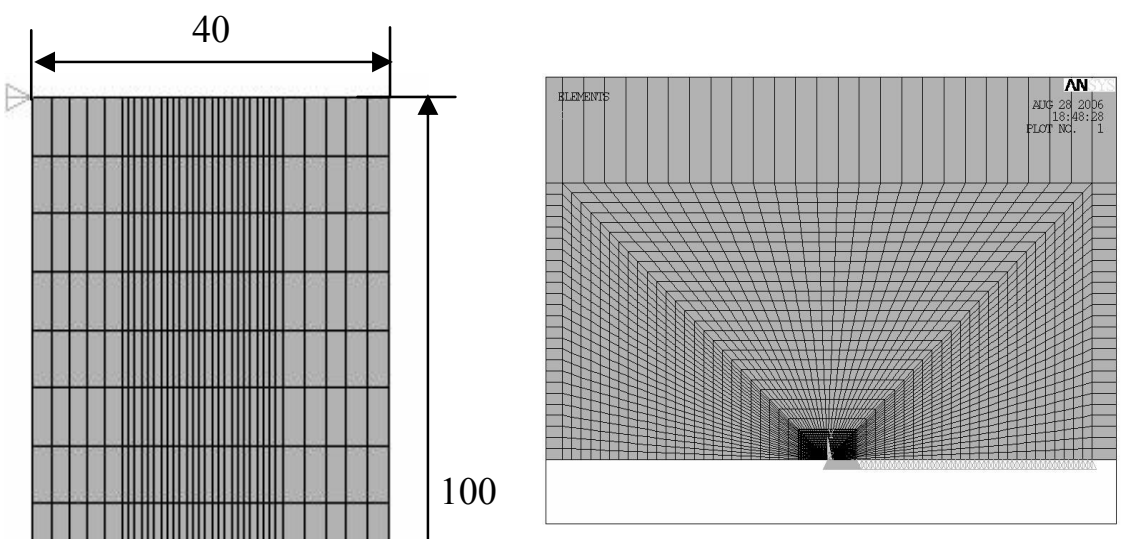

(b)

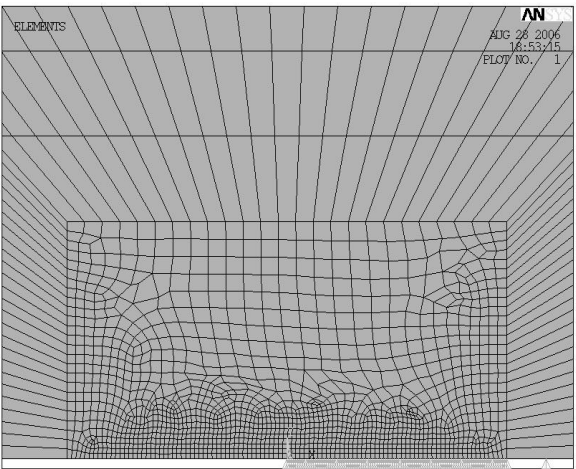

(c)

Fig. 7 Mesh Model of Three-Point Bend Specimen for Static Fracture Toughness Test: (a) Overview of the Model (b) Meshes Closes to the Crack Tip (c) Meshes at the Crack Tip

\section{(3) Stress and Strain Intensity Factor at the crack tip}

A stress intensity factor is still considered to characterize the stress fields in viscoelastic material as far as the vicinity of the crack tip. Hence, the stress intensity factor at the crack tip is calculated using the equation:

$$
\sigma=\frac{K_{I}}{\sqrt{2 \pi r}}
$$

The above equation can be normalised as,

$$
\frac{\sigma}{\sigma_{o}}=\frac{K_{I}}{\sigma_{o} \sqrt{a} \sqrt{2 \pi(r / a)}} \quad \sigma_{o}=\frac{P \times S}{1.072 \times b h^{2}}
$$

where $\sigma$ is the peak value of the stress in y direction, $\sigma_{0}$ is the nominal bending stress for three-point bending test, $\mathrm{K}_{\mathrm{I}}$ is the stress intensity factor $(\mathrm{MPa} \sqrt{\mathrm{m}}), \mathrm{r}$ is the distance along the ligament, $\mathrm{a}$ is the crack length, $\mathrm{P}$ is the applied load, $\mathrm{S}$ is a span length and $\mathrm{b}$ and $\mathrm{h}$ are the length and width of the beam cross section, respectively.

The numerical results fall on a straight line on the log-log plot of the normalized stress and the normalized distance diagram and the gradient is $-1 / 2$ that identifies the singularity of LEFM. Using a least square curve fitting method, the equation of the line is obtained, and then the stress intensity factor at the crack tip is calculated using Eq. (4).

Similarly to the stress intensity factor, the strain intensity factor is defined by the 
equation:

$$
\varepsilon=\frac{K_{\varepsilon}}{\sqrt{2 \pi r}}
$$

The above equation can be normalised as,

$$
\frac{\varepsilon}{\varepsilon_{o}}=\frac{K_{\varepsilon}}{\varepsilon_{o} \sqrt{a} \sqrt{2 \pi(r / a)}} \quad \varepsilon_{o}=\sigma_{o} / E
$$

where $\varepsilon$ is the maximum strain in y direction at the vicinity of the crack tip, E is Young's modulus and $\mathrm{K}_{\varepsilon}$ is the strain intensity factor at the crack tip. Young's modulus for static and dynamic numerical analysis are 11.76 and $17 \mathrm{GPa}$, respectively.

For three-point bend specimen model of GFRP under static loading, stress singularity ahead the crack tip is examined.

Normalized $\sigma_{y}$ is plotted as a function of normalized distance from the crack tip on a logarithm diagram as shown in Fig. 8. The fitting equation to the results is obtained as $y=-$ $0.50 \mathrm{x}+\mathrm{c}$ in the region of $\log (\mathrm{r} / \mathrm{a})$ between -3.5 and -1.5 . It is confirmed that stress singularity for linear elastic material is represented by the used mesh model. Normalized $\varepsilon_{\mathrm{y}}$ ahead of the crack tip is plotted in the same manner. For the strain, the same singularity is also confirmed.

In the case of intermediate loading rate $K$ of $1 \times 10^{3} \mathrm{MPa} \sqrt{\mathrm{m}} / \mathrm{s}$, the same singularities are also confirmed as shown in Fig. 9. In dynamic loading case, the stress and the strain singularity fields occupy a narrow region very near the crack tip as shown in Fig. 10.

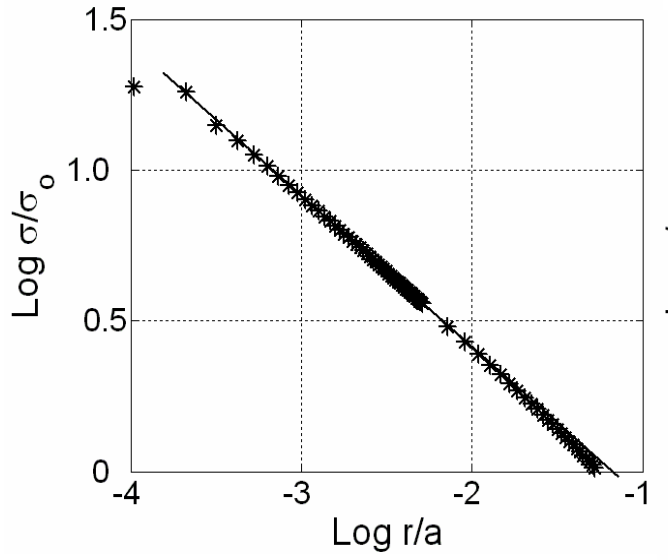

(a) Stress Singularity

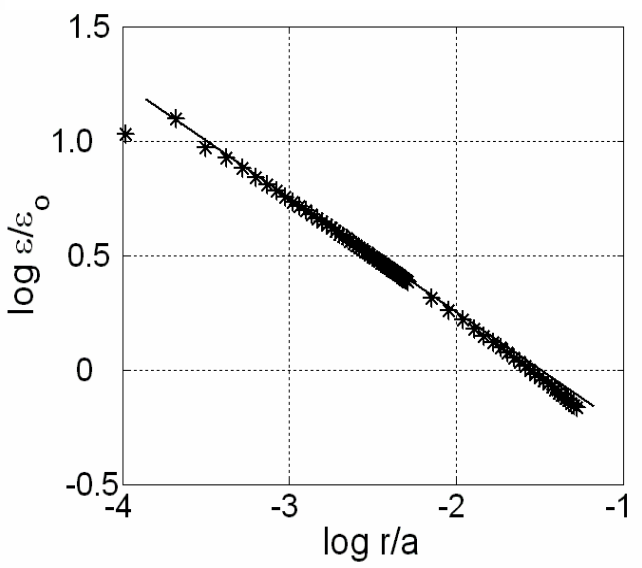

(b) Strain Singularity

Fig. 8 Stress and Strain Singularities ahead of the Crack Tip under Static Loading

\section{Discussion}

It is confirmed in the previous section that the stress and strain singularities of $1 / \mathrm{V}_{\mathrm{r}}$ are present at the crack tip for viscoelastic material. In this section, fracture toughness based on the stress and the strain will be evaluated and discussed.

Fracture toughness is evaluated by three methods. One is based on the strain gage method used in the experiment and the others are based on the stress and strain singularities at the crack tip, Eqs. (4) and (6). The results are indicated for three loading rates in Table 3. As seen, the static fracture toughness value evaluated by first two methods is quite well 
agrees with each other. The difference between both the fracture toughness values is around $5 \%$. This suggests that the FEM model used here is reasonable.

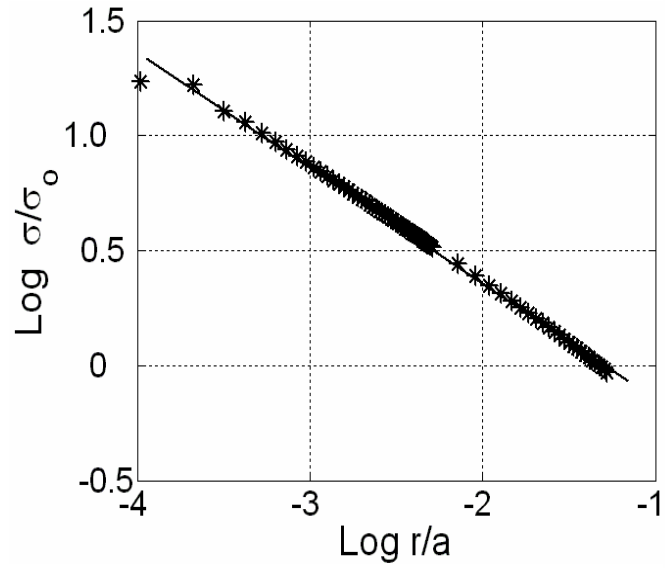

(a) Stress Singularity

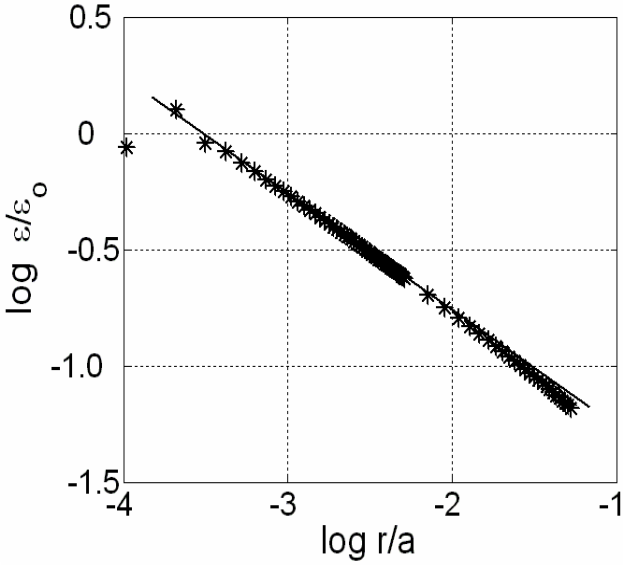

(b) Strain Singularity

Fig. 9 Stress and Strain Singularities ahead of the Crack Tip under Intermediate Loading

$$
\left(\dot{K}=1 \times 10^{3} \mathrm{MPa} \sqrt{\mathrm{m}} / \mathrm{s}\right)
$$

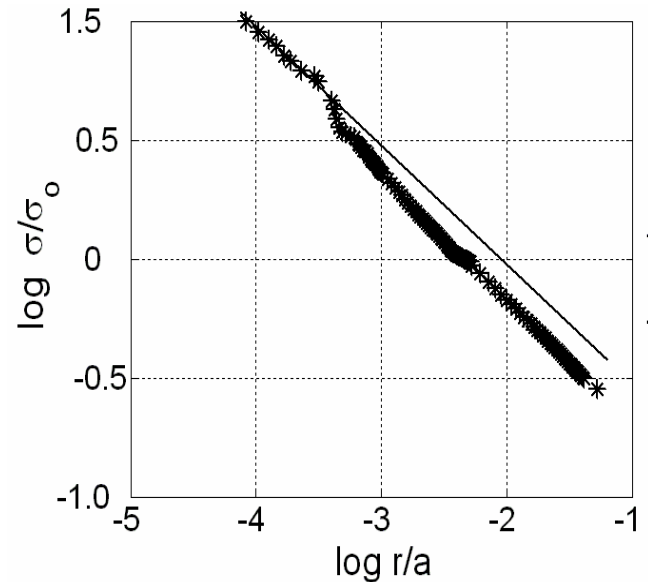

(a) Stress Singularity

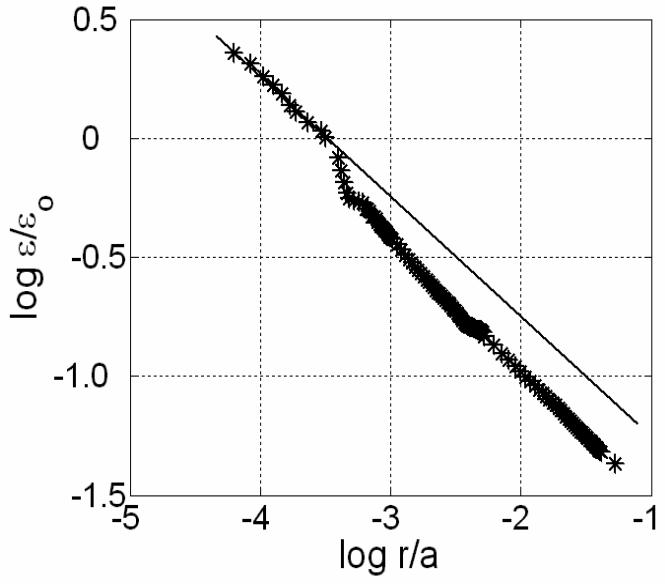

(b) Strain Singularity

Fig. 10 Stress and Strain Singularities ahead of the Crack Tip under Dynamic Loading

$$
\left(\dot{K}=1 \times 10^{6} \mathrm{MPa} \sqrt{\mathrm{m}} / \mathrm{s}\right)
$$

However, in cases of the intermediate and the high loading rate, fracture toughness values evaluated by the first two methods are remarkably different. It should be noted that the strain gage method used in the experiment could not be used for viscoelastic materials such as GFRP used in this work, because the stress singular field is developed in the narrow region very near the crack tip as shown in Fig. 10.

Fracture toughness based on the stress singularity is significantly affected by the loading rate, while one based on the strain singularity is less affected by the loading rate as shown in Table 3. It suggests that for the viscoelastic materials used in this work, the strain is a factor to control the fracture. Strain-controlled fracture is identified commonly in viscoelastic material $^{(16)}$ and other inelastic materials ${ }^{(17)}$. 
Table 3 Fracture Toughness of GFRP for Three Loading Rates

\begin{tabular}{|c|c|c|c|c|}
\hline $\begin{array}{c}\text { Loading } \\
\text { Rate } \\
(\mathrm{MPa} \sqrt{\mathrm{m}} / \mathrm{s})\end{array}$ & $\begin{array}{c}\text { Young's } \\
\text { Modulus } \\
(\mathrm{GPa})\end{array}$ & $\begin{array}{c}\text { K1c by Strain } \\
\text { Gauge }(\mathrm{MPa} \sqrt{\mathrm{m}})\end{array}$ & $\begin{array}{c}\text { K1c by Eq. } \\
(4) \\
(\mathrm{MPa} \sqrt{ } \mathrm{m})\end{array}$ & $\begin{array}{c}\text { Strain Intensity } \\
\text { Factor by Eq. (6) }\end{array}$ \\
\hline 1 & 11.8 & 7.0 & 7.4 & $4.2 \mathrm{E}-4$ \\
\hline $1 \times 10^{3}$ & 11.8 & 8.3 & 63.9 & $4.0 \mathrm{E}-4$ \\
\hline $1 \times 10^{6}$ & 17.0 & 12.0 & 80.1 & $7.8 \mathrm{E}-4$ \\
\hline
\end{tabular}

In GFRP, extensive damage takes place preceding the crack initiation. The damage zone shape under static and the intermediate loading rates were similar because damage zone increases in both length and width and then the width was saturated while the length continuously increases. It is in contrast with the dynamic case where the length and the width of the damage zone increase together with applied load.

The damage in GFRP is shown by observation through the scanning electron microscopic (SEM) across the thickness of the damaged specimen in Fig. 5. The damage zone consists of matrix cracking followed by debonding between fiber and matrix, and then fiber pulling out. In case where interfacial strength is higher than the fiber strength, fiber breaking occurs. In polymer reinforced by random chopped strand mat of the glass fiber, debonding is a dominant failure mechanism.

In order to understand the debonding mechanism in random chopped strand mat glass fiber reinforced polymer, the static and dynamic debonding tensile test was carried out for the round bar specimens having a single fiber bundle in the center ${ }^{(16)}$. The debonding test was carried out on the weakest direction of the fiber bundle i.e. parallel to the fiber bundle longitudinal direction. Under dynamic loading, the strain pulse amplitudes were around $3500 \mu \varepsilon$ and $4000 \mu \varepsilon$ to initiate debonding for $1 \mathrm{~mm}$ and $2 \mathrm{~mm}$ fiber bundles, respectively. On the static case, debonding initiation stresses were 9.0 and 19.6 MPa. Because GFRP is considered as an elastic material under static loading, the strain to initiate debonding is calculated by simply dividing the debonding initiation stress with the Young's modulus. Therefore, the strains to initiate debonding under static loading are approximately $765 \mu \varepsilon$ and $1667 \mu \varepsilon$ for $1 \mathrm{~mm}$ and $2 \mathrm{~mm}$ fiber bundles, respectively. These experimental results suggest that dynamic debonding initiation strain are higher than the static case.

For localization of fracture, a circumferential notch was introduced to the specimens of debonding test. It was indicated that stress concentration presents near the notch root, but the notch depth has no effect on the debonding initiation stress ${ }^{(16)}$. This debonding test result can be applied to understand the debonding mechanisms inside the polymer reinforced by chopped strand mat fiber used in this work because the debonding of the fiber and the matrix is caused by the main crack surrounding the fiber as illustrated in Fig. 11. This situation is very similar to that in the debonding test.

In the fracture toughness test specimen, fiber alignment might be in parallel, perpendicular or oblique to the crack plane. In the ideal case of the perpendicular fiber ahead of the crack tip, the mechanism of the fracture is shown in Fig. 11. If the interfacial strength is low, preceded by matrix cracking, the crack initiation takes place according to the following sequences: debonding at the interface between fiber and the matrix, extension of the debonding length to the fiber end, and the fiber pulling out from the matrix. In the case of high interfacial strength, the debonding does not extend to the fiber end, but may stop at certain position to result in the fiber breaks as shown in Figs. 11 (i) to (iii). 


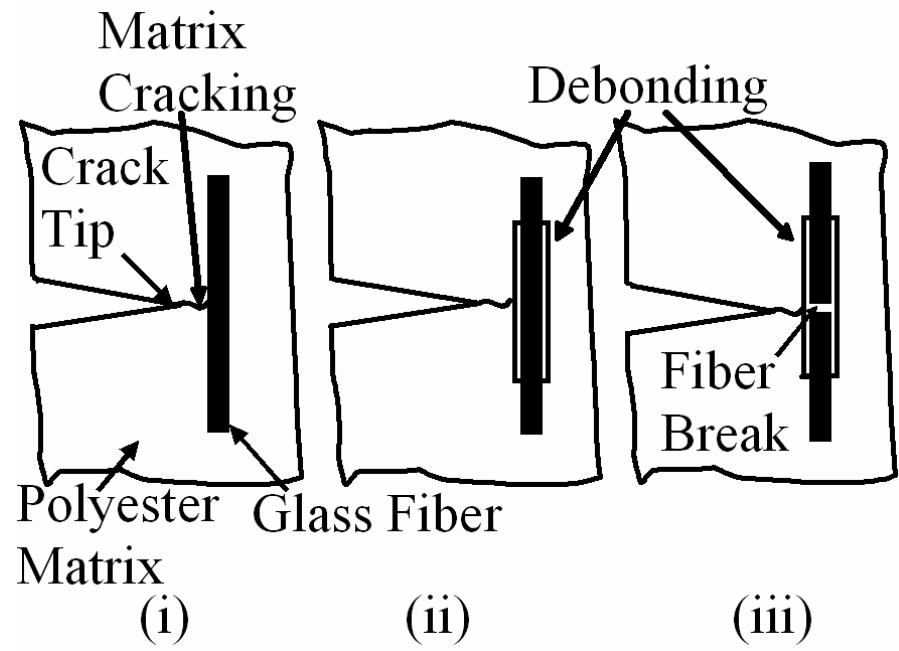

Fig. 11 Schematic Representation of the Debonding and Fiber Fracture Mechanisms in the Case of the Fiber Position Perpendicular to the Crack Plane: (i) Matrix Cracking (ii)

Debonding Initiation (iii) Fiber Fracture

The strain intensity factor at the crack tip under dynamic loading calculated by the finite element method is approximately twice as large as the static one as shown in Table 3. Dynamic debonding initiation strain for $2 \mathrm{~mm}$ fiber bundle is also approximately twice as large as the static one ${ }^{(18)}$. If it is assumed that the debonding process dominates the crack initiation in the fracture toughness test of GFRP, it is reasonable that the dynamic fracture toughness based on the strain is around twice as large as the static fracture toughness.

\section{Conclusion}

Over the wide range of the loading rates, fracture toughness test using the strain gage method and the numerical analysis method were carried out for the GFRP material. Fracture toughness based on the strain can explain the fracture behaviours for viscoelastic materials, but the loading rate effect cannot be fully explained from the aspect of viscoelastic property. Interfacial bonding strength under different loading rates must be considered to fully understand the loading rate effect on the dynamic fracture toughness.

\section{Acknowledgement}

The authors gratefully acknowledge the financial support from HORI Foundation.

\section{References}

(1) Oguni, K. and Ravichandran, K., Dynamic Compressive Behavior of Unidirectional E-glass/Vinylester Composites, Journal of Materials Science, Vol.36 (2001), pp.831-838

(2) Ochola, R.O., Marcus, K., Nurick, G.N, Franz, T., Mechanical Behavior of Glass and Carbon Fibre Reinforced Composites at Varying Strain Rates, Composite Structures, Vol.63 (2004), pp.455-467

(3) Jang, B.Z., Lieu, Y. K., Fracture Behavior of Short Fiber Reinforced Thermoplastic I, Crack Propagation Mode and Fracture Toughness, Applied Polymer Science, Vol.30 (1985), pp.3925-3942

(4) Mandel, J. F., Huang, D. D., Mc. Garry, F. J., Crack Propagation Modes in Injection Molded Fiber-reinforced Thermoplastics, Short Fiber Reinforced Composite Materials, ASTM STP 772 (1982), pp.3-32

(5) Todd, M.Mower and Victor, C. Li, Fracture Characterisation of Random Short Fiber Reinforced Thermoset Resin Composites, Engineering Fracture Mechanics, Vol.26, 
No.4 (1987), pp. 593-603

(6) Owen, M.J and Bishop, P.T., Critical Stress Intensity Factors Applied to Glass Reinforced Polyester Resins, J. Composite Material, Vol.7 (1973), pp.146-159

(7) Alexander, R.M., Schapery, R. A., Jerina, K.L. and Sanders, B. A., Fracture Characterisation of a Random Fiber Composite Materials, ASTM STP 772 (1982), pp.208-224

(8) Gaggar, S. and Broutman, L.J., Fracture Toughness of Random Glass Fiber Epoxy Composites: An Experimental Investigation. Flaw Growth and Fracture, ASTM STP 631 (1977), pp.310-330

(9) Meunier, M., Shenoi, R.A., Dynamic Analysis of Composite Sandwich Plates With Damping Modelled Using High-order Shear Deformation Theory, Composites Structures, Vol.54 (2001), pp.243-254

(10) Georgiadis, H., Plane Impact of Crack Viscoelastic Body, Intl. J. Engineering Science, Vol.29, No.2 (1991), pp.171-177

(11) Georgiadis, H., Finite Length Crack Moving in a Viscoelastic Strip Under Impact-II, Engineering Fracture Mechanics, Vol.29, No.3 (1988), pp.355-363

(12) Gunter, L. Domani, An Investigation of a Dynamic Crack Propagation in Two-dimensional Viscoelastic Solid, Engineering Fracture Mechanics, Vol.46, No.5 (1993), pp.807-813

(13) Shirley Savet Lana, Homma, H., Nakazato, K., Viscoelastic Effect on the Fracture Toughness of GFRP: Experimental Approach, Key Engineering Materials, Vols.306-308 (March 2006), pp.745-750

(14) Dally and Stanford, Strain-gage Methods for Measuring the Opening-mode Stress Intensity Factor, $\mathrm{K}_{1}$, Experimental Mechanics, Vol.27, No.4 (1987), pp.381-388

(15) Yanada, H. and Homma, H., Study on the Fracture Toughness Evaluation of FRP, J. of Material Science, Vol.18 (1983), pp.133-139

(16) Abdel-Tawab, K. and Weitsman, Y. J., A strain-based Formulation for the Coupled Viscoelastic Damage Behaviour, J. of Applied Mechanics, Vol.68 (2001), pp.304-311

(17) Nalla, R. K., Kinney, J. H. and Ritchie, R. O., On the Fracture of Human Dentin: Is It Stress-or Strain-controlled?, Lawrence Berkeley National Laboratory, Paper LBNL-51378 (2006)

(18) Homma, H., Gunawan, F., Yamauchi, M., and Fenny, K., Interfacial Strength of Glass Fiber Composite, Key Engineering Materials, Vols.243-244 (2003), pp.81-86 